\title{
Utilization of Construction Waste Tiles as a Replacement for Fine Aggregates in Concrete
}

\author{
Adebola A. Adekunle \\ Department of Civil Engineering \\ Federal University of Agriculture \\ Abeokuta, Nigeria \\ adebolamay@gmail.com
}

\author{
Kuye R. Abimbola \\ Department of Civil Engineering \\ Federal University of Agriculture \\ Abeokuta, Nigeria \\ kuyeabimbola06@gmail.com
}

\author{
Ayo O. Familusi \\ Department of Civil Engineering \\ Federal University of Agriculture \\ Abeokuta, Nigeria \\ ayomacfamilson@gmail.com
}

\begin{abstract}
Ceramic wastes are found to be suitable for usage as substitution for fine and coarse aggregates in concrete production. This study is an investigation into the utilization of waste tiles as partial replacement for fine and coarse aggregates in concrete. The control mix and other mixes containing cement, water, granite and partial replacement for sand with crushed tiles (in $5 \%, 10 \%, 15 \%$ and $20 \%$ proportions) were cast, cubed, cured and crushed. Also, another mix containing cement, water, sand and partial replacement of granite with crushed tiles (in $25 \%, 50 \%$ and $75 \%$ proportions) were cast, cubed, cured and crushed. The specimens were tested for their respective compressive strengths using the Universal Testing Machine (UTM) on the $7^{\text {th }}, 14^{\text {th }}, 21^{\text {st }}$ and $28^{\text {th }}$ days of curing. At 28 days, the compressive strength value of $5 \%$ of fine-waste tiles replacement was $20.12 \mathrm{~N} / \mathrm{mm}^{2}$ while that of $10 \%, 15 \%$ and $20 \%$ were $14.24 \mathrm{~N} / \mathrm{mm}^{2}, 11.04 \mathrm{~N} / \mathrm{mm}^{2}$ and $10.12 \mathrm{~N} / \mathrm{mm}^{2}$ respectively. Moreover, at 28 days, the compressive strength of $25 \%$ of coarsewaste tiles replacement shows an increase to $22.45 \mathrm{~N} / \mathrm{mm}^{2}$ while that of $50 \%$ and $75 \%$ were $18.4 \mathrm{~N} / \mathrm{mm}^{2}$ and $12.2 \mathrm{~N} / \mathrm{mm}^{2}$ respectively. Thus it can be concluded that fine aggregates can be substituted at $5 \%$ waste tiles while coarse aggregates can be substituted at $25 \%$ waste tiles.
\end{abstract} tiles

Keywords-concrete; deviation; gradation; replacement; waste

\section{INTRODUCTION}

Aggregate is one of the most important materials in use for concrete production as it profoundly influences concrete properties and performance. And not much research has been done on incorporating normal ceramic wall tiles waste as partial substitute of fine aggregates or cement, in the production of structural concrete. The current research is a bid towards exploring the possibility of incorporating wastes from ceramic wall tiles as partial substitute of fine aggregates or cement in the making of concrete. From economic point of view, cement and fine aggregates contribute a bigger portion of costs in the production of concrete, thus to have them replaced by waste material of similar characteristics is a major economic gain, while being more environment friendly. Ceramic wastes are found to be suitable for usage as substitution for fine and coarse aggregates and partial substitution in cement production. Researchers have indicated their potential for usage in both structural and non-structural concrete and even for mortars. They were found to be performing better than normal concrete, in properties such as density, durability, permeability and compressive strength [1]. The usage of waste tiles partially as a replacement for coarse aggregates will clear the wastes from construction and production site, also environmental pollution is reduced as impact of mining is reduced, natural resources are conserved and power consumption required for quarrying is minimized [2]. Compressive strength of concrete gradually increased with the increase of quantity of coarse waste ceramic tile aggregate up to certain limits i.e. $20 \%$ for water-cement ratio of $0.4,30 \%$ for water-cement ratio of 0.5 and $40 \%$ for water-cement ratio of 0.6 . The greatest compressive strength was observed for C5-10 concrete. It was noticed that the flexural strength of Optimal Waste Ceramic Concrete was $32.2 \%$ higher than flexural strength of Reference Concrete. Therefore, it can be concluded that the use of coarse waste ceramic tile content in the concrete enhanced the flexural strength considerably. Also, it can be seen that using waste ceramic tiles in concrete production causes no remarkable negative effect in the properties of concrete. The optimal case of using waste ceramic tiles as coarse aggregates is found to vary from 10 to 30 percent. In these measures, not only an increase happens in compressive strength, but also a decrease in unit weight occurs. Finally, using waste ceramic tiles in concrete is an effective measure regarding to reducing the costs of concrete and is environmentally cleaner clean along with wastage management and decreasing the use of natural raw materials [3]. In [4] it is affirmed that the increase in tiles powder leads to the increase in workability of concrete.

Tile powder behaves like admixtures, which can be used to produce Ready Mix Concrete. When crushed tiles replace coarse aggregate, compressive strength increases up to $10 \%$, but after that it decreases. The authors in [5] further confirm that ceramic waste can be used as coarse aggregate as the properties of ceramic waste coarse aggregate are within the range of the values of concrete making aggregate according to Indian Standards. The use of Crushed Tile Aggregate (CTA) caused a $40 \%$ loss in compressive and splitting tensile strengths. CTA has negatively affected abrasion and freezethaw durability. According to these results, $100 \%$ replacement of CTA as a coarse aggregate is not appropriate. The use of CTA in concrete has positive effects on the environment and obtaining lower costs [6]. Tile aggregate concrete is little bit more economical as compared to conventional concrete. As an estimate for making $1 \mathrm{~m}^{3}$ of concrete by substituting $20 \%$ 
normal $20 \mathrm{~mm}$ aggregates with tile aggregates about $16 \%$ money can be saved on total amount of $20 \mathrm{~mm}$ aggregates. By addition of ceramic tile waste into concrete, proper effective utilization of ceramic tile waste can be achieved [7]

\section{MATERIALS AND METHODS}

\section{A. Materials Used for the Study}

These include Ordinary Portland Cement, waste tiles (which were collected from building site in Lagos, Nigeria), Coarse aggregates (granite) and Fine aggregates (sand).

\section{B. Experimental Procedure}

The Sieve Analysis was carried out in accordance with the procedure given in BS 812 and the gradation test was performed on the samples of aggregates (sand, granite and waste tiles) in the laboratory. The batching of concrete test samples was by weight in order to eliminate errors due to variations the mix proportion adopted was 1:2:4 by weight of cement, fine and coarse aggregates and the water/cement ratio by weight of 0.6 , crushed granite aggregate with maximum size of $12.7 \mathrm{~mm}$ was mixed with sand-cement mixture. The control mix containing cement, sand, granite and water was mixed and cast. Cubes were then made from the mix and cured for 7,14 , 21 and 28 days respectively before they were crushed using the Universal Testing Machine.

TABLE I. WEIGHT OF CRUSHED TILE AS REPLACEMENT FOR FINE AGGREGATES

\begin{tabular}{|c|c|c|c|c|}
\hline $\begin{array}{c}\text { Tile } \\
\text { Replacement } \\
(\%)\end{array}$ & $\begin{array}{c}\text { Cement } \\
(\mathbf{k g})\end{array}$ & Sand (kg) & $\begin{array}{c}\text { Granite } \\
(\mathbf{k g})\end{array}$ & $\begin{array}{c}\text { Tiles } \\
(\mathbf{k g})\end{array}$ \\
\hline 0 & 13.89 & 27.77 & 55.54 & - \\
\hline 5 & 13.89 & 26.38 & 55.54 & 1.39 \\
\hline 10 & 13.89 & 24.99 & 55.54 & 2.78 \\
\hline 15 & 13.89 & 23.6 & 55.54 & 4.77 \\
\hline 20 & 13.89 & 22.22 & 55.54 & 5.55 \\
\hline
\end{tabular}

TABLE II. WEIGHT OF CRUSHED TILE AS REPLACEMENT FOR COARSE AGGREGATES

\begin{tabular}{|c|c|c|c|c|}
\hline $\begin{array}{c}\text { Tile } \\
\text { Replacement } \\
(\%)\end{array}$ & $\begin{array}{c}\text { Cement } \\
(\mathbf{k g})\end{array}$ & Sand (kg) & $\begin{array}{c}\text { Granite } \\
\mathbf{( k g )}\end{array}$ & $\begin{array}{c}\text { Tiles } \\
(\mathbf{k g})\end{array}$ \\
\hline 0 & 13.89 & 27.77 & 55.54 & - \\
\hline 25 & 13.89 & 27.77 & 41.68 & 13.86 \\
\hline 50 & 13.89 & 27.77 & 27.77 & 27.77 \\
\hline 75 & 13.89 & 27.77 & 13.89 & 41.66 \\
\hline
\end{tabular}

Other mixes as shown in Table I containing cement, water, granite and partial replacement for sand with crushed tiles (in $5 \%, 10 \%, 15 \%$ and $20 \%$ ) were also cast, cubed, cured and crushed following the same process for the control mix. Also, another mix as shown in Table II containing cement, water, sand and partial replacement of granite with crushed tiles (in $25 \%, 50 \%$ and $75 \%$ ) were also cast, cubed, cured and crushed using the same process above. The specimens were tested for their respective compressive strengths using the Universal Testing Machine (UTM) on the 7th, 14th, 21st and 28th days of curing and data for their respective compressive strengths were collated from the tests.

\section{RESULTS AND DISCUSSION}

The sieve analysis revealed that most of the coarse waste tile materials were within the range between $2.5 \mathrm{~mm}$ to $19 \mathrm{~mm}$ in particle size diameter with a fairly good gradation pattern, and the nominal maximum particle size diameter was $12.5 \mathrm{~mm}$. While for fine materials, the analysis showed that most of the fine waste tiles material was within the range between $0.2 \mathrm{~mm}$ to $2.5 \mathrm{~mm}$ in particle size diameter with a very good gradation pattern, and the nominal maximum particle size diameter was $4.75 \mathrm{~mm}$, as shown in Figures 1 and 2 .

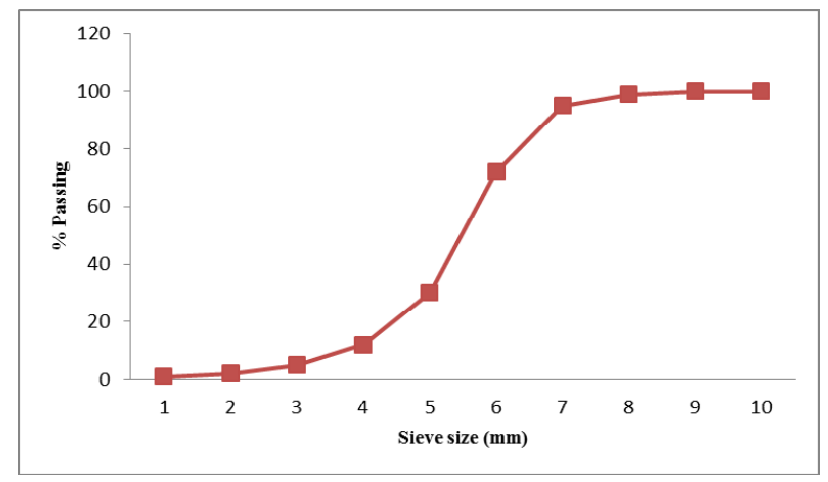

Fig. 1. Grain Size Distribution Curve of Waste Tile Coarse Aggregates.

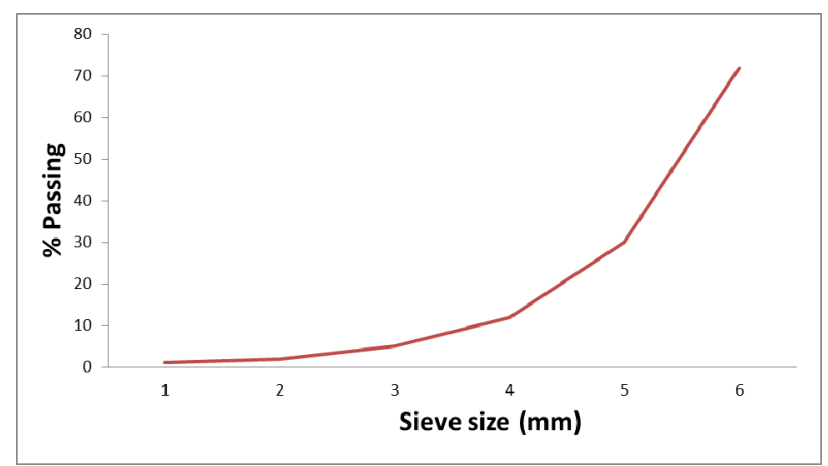

Fig. 2. Grain Size Distribution Curve of Waste Tile Fine Aggregates

At 7 days, the compressive strength value of $5 \%$ of waste tiles replacement showed a considerable high compressive strength of $14.57 \mathrm{~N} / \mathrm{mm}^{2}$ as compared to the other three batches which were $12.9 \mathrm{~N} / \mathrm{mm}^{2}, 12.6 \mathrm{~N} / \mathrm{mm}^{2}, 8.85 \mathrm{~N} / \mathrm{mm}^{2}$ respectively while at 14 days, the compressive strength value of $5 \%$ of waste tiles replacement had increased to $14.89 \mathrm{~N} / \mathrm{mm}^{2}$ while that of $10 \%, 15 \%$ and $20 \%$ were $14.69 \mathrm{~N} / \mathrm{mm}^{2}, 11.14 \mathrm{~N} / \mathrm{mm}^{2}$ and $9.39 \mathrm{~N} / \mathrm{mm}^{2}$ respectively. At 28 days, the compressive strength value of $5 \%$ of waste tiles replacement was 20.12 $\mathrm{N} / \mathrm{mm}^{2}$ while that of $10 \%, 15 \%$ and $20 \%$ were $14.24 \mathrm{~N} / \mathrm{mm}^{2}$, $11.04 \mathrm{~N} / \mathrm{mm}^{2}$ and $10.12 \mathrm{~N} / \mathrm{mm}^{2}$ respectively as these were evident from Figure 3. These results when compared with a grade 20 concrete which was the target, showed that $5 \%$ waste tile replacement were adequate as fine aggregate replacement. 
Moreover, there were variations in the compressive strength of the concrete with partial replacement of waste tiles as coarse aggregates. At 7 days, the compressive strength of $25 \%$ of waste tiles replacement showed a considerable high compressive strength of $19.2 \mathrm{~N} / \mathrm{mm}^{2}$ as compared to the other two replacement batches which were $9.51 \mathrm{~N} / \mathrm{mm}^{2}$ and 6.52 $\mathrm{N} / \mathrm{mm}^{2}$ respectively and while at 28 days, the compressive strength of $25 \%$ of waste tiles replacement shows an increase to $22.45 \mathrm{~N} / \mathrm{mm}^{2}$ while that of $50 \%$ and $75 \%$ were $18.4 \mathrm{~N} / \mathrm{mm}^{2}$ and $12.2 \mathrm{~N} / \mathrm{mm}^{2}$ respectively. These results when compared with a grade 20 concrete which was the target, showed that $25 \%$ waste tile replacement were adequate as coarse aggregate replacement.

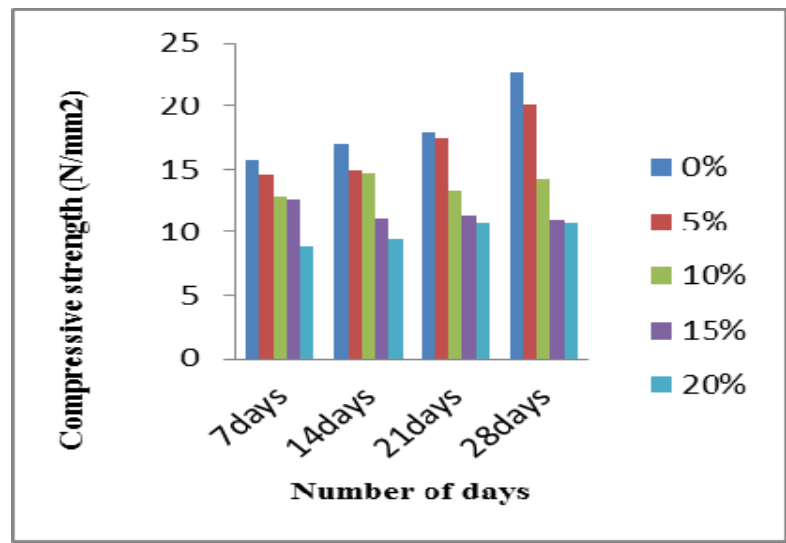

Fig. 3. Compressive Strength of Concrete with Waste Tiles as Fine Aggregates

It can be deduced that $5 \%$ fine-waste-tiles-concrete samples showed a small deviation in compressive strength of about $11.37 \%$ from the control sample compared with the other $10 \%$, $15 \%$ and $20 \%$ which gave $37.27 \%, 51.37 \%$ and $55.42 \%$ reduction in the compressive strength at 28 days respectively. This deviation when compared with the control samples showed that 5\% fine-waste-tiles-concrete samples were within the range of grade 20 concrete, while $20 \%$ replacement showed the largest deviation as shown in Table III. From Table IV below, it can be deduced that $25 \%$ coarse-waste-tiles concrete showed a minimal deviation of about $18.66 \%$ from the control sample compared with the other $50 \%$ and $75 \%$ which showed a reduction in the compressive strength of the control sample with $33.3 \%$ and $55.8 \%$ respectively. This deviation when compared with the control samples shows that $25 \%$ coarsewaste-tiles concrete samples were within the range of grade 20 concrete, while $75 \%$ coarse-waste-tiles concrete samples showed the largest deviation .

TABLE III. DEVIATION OF THE FINE-WASTE-TILE-CONCRETE FROM THE CONTROL SAMPLE

\begin{tabular}{|c|c|}
\hline $\begin{array}{c}\text { Fine-Waste-Tile- } \\
\text { Content (\%) }\end{array}$ & $\begin{array}{c}\text { \% Reduction in Compressive } \\
\text { Strength }\end{array}$ \\
\hline 5 & 11.37 \\
\hline 10 & 37.27 \\
\hline 15 & 51.37 \\
\hline 20 & 55.42 \\
\hline
\end{tabular}

TABLE IV. DEVIATION OF THE COARSE-WASTE-TILE-CONCRETE FROM THE CONTROL SAMPLE

\begin{tabular}{|c|c|}
\hline $\begin{array}{c}\text { Coarse-Waste-Tiles Content } \\
(\%)\end{array}$ & $\begin{array}{c}\text { \% Reduction in Compressive } \\
\text { Strength }\end{array}$ \\
\hline 25 & $18.66 \%$ \\
\hline 50 & $33.3 \%$ \\
\hline 75 & $55.8 \%$ \\
\hline
\end{tabular}

IV. CONCLUSIONS AND RECOMMENDATIONS

The suitability of ceramic waste as substitution of concrete aggregate elements varies and depends on the material being substituted and the percentage composition of the new mixure. From the experimental results, the following conclusions can be drawn:

- The compressive strength of 5\% fine-waste-tiles concrete showed a minimal deviation of $11.37 \%$ from the strength of the control sample at 28 days, thus it can be concluded that fine aggregates can be substituted at $5 \%$ waste tiles.

- The compressive strength of $25 \%$ coarse-waste-tiles concrete showed a minimal deviation of $18.66 \%$ from the strength of the control sample at 28 days, thus it can that concluded that coarse aggregates can be substituted at $25 \%$ waste tiles.

- Fine-waste-tile concrete $15 \%$ and $20 \%$ shows $51.37 \%$ and $55.42 \%$ reduction in the concrete strength to values of 11.04 $\mathrm{N} / \mathrm{mm} 2$ and $10.12 \mathrm{~N} / \mathrm{mm} 2$, values which were below the target grade 20 concrete. Thus, it cannot be recommended to substitute fine aggregates in concrete with these percentage replacements.

- Coarse-waste-tile concrete of $50 \%$ and $75 \%$ showed $33.3 \%$ and $55.8 \%$ reduction in the concrete strength to values of $18.4 \mathrm{~N} / \mathrm{mm} 2$ and $12.2 \mathrm{~N} / \mathrm{mm} 2$, values which were below the target grade 20 concrete. Thus, it cannot be recommended to substitute coarse aggregates in concrete with these percentage replacements.

- Adequate replacement of fine aggregate with waste tiles has been found to be $5 \%$. Beyond this limit, the concrete cube strengths did not meet code requirements for grade 20 concrete strength as per BS 1881 Part 4 (1997).

- Adequate replacement of coarse aggregate with waste tiles has been found to be $25 \%$. Beyond this limit, the concrete cube strengths did not meet code requirements for grade 20 concrete strength as per BS 1881 Part 4 (1997).

- With $5 \%$ and $25 \%$ waste-tile substitution of fine and coarse aggregate respectively, a cost reduction of $2.3 \%$ was achieved for every cubic meter of concrete produced.

Further study is recommended to extend this research to a wider perspective in order to be able to consider more parameters governing the effect on the behavior and engineering properties of fresh and hardened concrete containing different types and sizes of waste tile materials.

\section{REFERENCES}

[1] O. Zimbili, W. Salim, M. Ndambuki, "A Review on the Usage of Ceramic Wastes in Concrete Production", World Academy of Science, Engineering and Technology International Journal of Civil, 
Environmental, Structural, Construction and Architectural Engineering Vol. 8, No. 1, pp. 91-95, 2014

[2] P. C. Shetty, Varun, V. Kumar, N. Shetty, S. B. Poojary, "Study of strength properties using tile waste in concrete", International Journal of Combined Research and Development, Vol. 5, No. 4, pp. 659-662, 2016

[3] M. Daniyal, S. Ahmad, "Application of Waste Ceramic Tile Aggregates in Concrete", International Journal of Innovative Research in Science, Engineering and Technology. Vol. 4, No. 12, pp. 12808-12815, 2015

[4] K. C. Hemanth, R. K. Ananda, B. K. Sateesh, T. Guravaiah, N. Naveen, S. Jani, "Effect of Waste Ceramic Tiles in Partial Replacement of Coarse and Fine Aggregate of Concrete", International Advanced Research Journal in Science, Engineering and Technology Vol. 2, No. 6, pp 13-16, 2015
[5] P. Malik, J. Malhotra, A. Verma, P. Bhardwaj, A. Dhoundiyal, N. Yadav, "Mix Design for Concrete with Crushed Ceramic Tiles as Coarse Aggregate", International Journal of Civil Engineering Research, Vol. 5, No. 2, pp 151-154, 2014

[6] I. B. Topcu, M. Canbaz, "Utilization of Crushed Tile as Aggregate in Concrete", Iranian Journal of Science \& Technology, Transaction B, Engineering, Vol. 31, No. B5, pp. 561-565, 2007

[7] P. Singh, R. K. Singla, "Utilization of Waste Ceramic Tiles as Coarse Aggregate in Concrete", Journal of Multidisciplinary Engineering Science and Technology (JMEST) Vol. 2, No. 11, pp. 3294-3300, 2015 